\title{
Reduction of Radioactive Waste Through the Reuse and Recycle Policy of the Sealed Radioactive Sources Management
}

\author{
T. Marpaung \\ Senior Inspector of Radiation Safety, Nuclear Energy Regulatory Agency \\ Jl. Gajah Mada No. 8, Jakarta 10120, Indonesia
}

\section{ARTICLE INFO}

Article history:

Received 20 November 2010

Received in Revised form 11 June 2012

Accepted 30 August 2012

Keywords:

Reduce

Reuse

Recycle

Sealed source

Spent sealed source

DSRS

Radioactive waste

\begin{abstract}
A B S T R AC T
In the past few years, the utilization of sealed source for medical, industrial and research purposes has shown an accelerating increase. This situation will lead to increases in the amount of sealed radioactive. During its use, a sealed radioactive waste will eventually become either a spent sealed source or disused sealed radioactive source (DSRS), due to certain factors. The reduction of the amount of radioactive waste can be executed through the application of reuse and recycle of sealed source. The reuse and recycle policy for spent and disused sealed sources are not already specified yet. The reuse of spent sealed sources can be applied only for the sources which had been used in the medical field for radiotherapy, namely the reuse of a teletherapy Co- 60 source in a calibration facility. The recycle of a spent sealed source can be performed for radioactive sources with relatively high activities and long half-lives; however, the recycling activity may only be performed by the manufacturer. To avoid legal conflicts, in the amendment to the Government Regulation No.27 Year 2002 on Management of Radioactive Waste, there will be a recommendation for a new scheme in the management of radioactive waste to facilitate the application of the principles of reduce, reuse, and recycle.
\end{abstract}

(c) 2012 Atom Indonesia. All rights reserved

\section{INTRODUCTION}

Sealed radioactive sources are currently in widespread use, and their use continually grows from year to year. This development potentially causes the generation rate of sealed source radioactive wastes (SSRWs) to increase. Even now, the SSRW is the predominant type of radioactive waste received by Badan Tenaga Nuklir NasionalBATAN (National Nuclear Energy Agency) from the user, as the producer of the SSRW, to be managed in the Radioactive Waste Management Facility at BATAN.

A sealed source which is no longer in use becomes an SSRW only after it is so declared. Before it is declared as an SSRW, the no longer used source is classified as either a spent sealed source or a disused sealed source. Both spent and disused sealed sources are themselves considered as significant issues by the IAEA, and their radiation safety and security is controlled by regulatory bodies. After they are declared as SSRWs, however, the responsibility

\footnotetext{
* Corresponding author.

E-mail address: t.marpaung@bapeten.go.id
}

for their management passes to implementing agencies.

Regulatory bodies control and regulate spent and disused sources. Those bodies control and regulate not only the radiation safety and security of those sources, but also the application of the "reduce, reuse, and recycle" concept on those spent and disused sealed sources until they enter the waste regime. Also, if the "reuse and recycle" concept can be applied optimally, then the aim of one of the nine basic principles for radioactive waste management, namely "Control of radioactive waste generation", which means minimizing the generation of radioactive wastes as far as practicable, will be fulfilled, since the application of reuse and recycle will reduce the production of spent and disused sealed sources.

In this paper, the author conducts a literature review on several regulatory documents and, based on those documents, recommends a new policy which may be followed for applying reduce, reuse and recycle principles on spent and disused sealed sources.

The remainder of this paper is organized as follows. Section 2 delineates the safety and security 
aspects of spent and disused sources, which becomes the topic for further discussions. Section 3 describes and explains the "reduce, reuse, and recycle" principle as applied to spent and disused sealed sources. Section 4 explains the potential legal conflicts facing the presently followed BAPETEN and BATAN policy on the reuse of spent and disused sealed sources, describes a proposed new policy which solves the problem, and explains the reasoning behind it. And finally, Section 5 presents the conclusions and the recommendations.

\section{SAFETY AND SECURITY ASPECT OF SPENT AND DISUSED SEALED SOURCES}

A sealed source is any radioactive material, other than reactor fuel elements, which is permanently sealed in a capsule, or is closely bonded, and is in a solid form. During its use, due to various factors, a sealed source will eventually reach either one of two conditions, namely becoming (1) a spent sealed source, or (2) a disused sealed source. Under those conditions, the source is known as a "waste candidate" (a disused sealed radioactive source). Only afterward will it be declared as radioactive waste [1]. IAEA recommends that the safety and security of such spent and disused sealed sources be controlled by a state regulatory body.

\section{Radiation safety}

Since its beginning, the usage of nuclear energy has been required to follow appropriate regulations regarding radiation safety. Users of sealed sources are required to fulfill radiation safety requirements until there is a change in the ownership status of the source. The change in ownership status may have various causes, including, among others, the transfer of authority over the source by the law, such as re-export to the country of origin or the allocation to BATAN as a result of its being declared as radioactive waste. Radiation safety requires an optimal effort in applying radiation protection on radioactive sources so that no radiation accidents occur. There are three main features of radiation safety, namely: (1). Safety aspects intrinsic to activity (2). probabilistic analysis, and (3). transparentcy [2].

\section{Security of radioactive source}

The security requirements on sealed radioactive sources must also be fulfilled by the users, starting from their importation onwards, including during their use, transportation and storage. This is especially true for Category 1 and Category 2 items. The security of radioactive sources requires a comprehensive effort to implement the physical protection of radioactive sources so as to prevent theft or sabotage. The Physical Protection System is an appropriate integration of qualified personnel, standard equipment, and procedures. There are three main features of the security of radioactive source: (1). malevolent activity (2). threat based judgment, and (3). confidentiality [2,3].

\section{REDUCE, REUSE AND RECYCLE CONCEPT FOR SPENT AND DISUSED SEALED SOURCES}

Here, the "reduce, reuse, and recycle" concept for spent and disused sealed sources is explained. We must first define what is meant with the terms "spent sealed source" and "disused sealed source". Generally it can be interpreted that a spent sealed source or disused sealed source is a used sealed source. If the spent sealed source can not be used again or reused, then the spent source becomes a disused source. IAEA has used the term "disused sealed radioactive sources" (DSRS) for both spent and disused sources. IAEA considers the existence of DSRS a cause of serious concern, and therefore conducted the seminar "Regional Seminar of Radiation Protection Regulators: Sharing Best Practices in Managing disused Sources and Networking" in the Asian region to discuss it. In the seminar, held on December 7 to 11, 2009 in Jakarta, was attended by 15 countries which sent 24 participants and 3 persons as observers. Prior to the seminar, the IAEA had organized a similar event, namely the IAEA/ANSN International Workshop on Sustainable Management of disused Sealed Radioactive Sources (DSRS): Working Towards Disposal, from December 12, 2008 to January 16, 2009 in Chiang Mai, Thailand, which was attended by around 80 of managers and experts from 23 countries [1].

In exacting terms, the term "spent saled source" and "disused sealed sources" are defined as follows:

1. Spent sealed source: a source that is no longer suitable for its intended purpose as a result of radioactive decay, a spent source may still represent radiological hazard.

2. Disused sealed source: a source no longer in use or intended to be used (and is not intended to be used, for the practice for which an 
authorization has been granted), a disused sealed sources may still represent a significant radiological hazard. It differs from a spent source in that it may still be capable of performing its function; it may be disused because it is no longer needed.

The factors causing sealed radioactive sources to become spent or disused are as follows:

a. decay factor is a major and general factor; it causes sealed source to eventually become disused sealed source (initially spent, finally disused).

b. damage factor such as leakage of radioactive source. Although the potential for leakage of radioactive sources is very small because the radioactive source has been tested according to the certification test for the sealed source (ISO 2919), it cannot be totally ignored. Damages may occur during operations, such as during emergency situations (emergency stuck source) in well logging, during brachytherapy-remote afterloading, or during the use of industrial radiography camera.

c. prohibition factor namely the principle that the benefits (justify) are considered to be not useful anymore (unjustify), such as banning the use of some medical procedures such as manual brachytherapy (Ra-226, Cs-137, Co-60) and Teletherapy (Cs-137), or the use of Ra-226 in industrial or consumer products such as lightning rod, or glow-in-the-dark clock markers and hands.

d. other factors such as a misconfigured new equipment, which includes a radioactive source from its manufacturer which cannot be used with the equipment, then the equipment will enter the disused sealed source regime [4,5].

With the above understanding regarding the spent and disused sealed sources which form the focus of this work, the concept of "reduce" and "reuse and/or recycle" will be further explained in the rest of this section.

\section{Reduce}

The "reduce" concept, when applied on spent and disused sealed sources, has a different meaning from its use in the management of other solid radioactive wastes. It is not possible to directly minimize the volume of a SSRW. In contrast, for solid radioactive wastes, namely radioactive wastes which are in a solid phase, their amounts and volumes can be reduced with the principles of radioactive waste processing, e.g. by incineration or compaction.

The waste volume and amount minimization principle ("reduce") can be done through the reuse and recycle application of the sealed source in the medical, industry and research fields. In general, the minimization principle can be applied through the use of radionuclides with relatively short half-lives, so that the radioactive sources quickly decay to relatively low activity levels.

Waste minimization is an important step in managing waste and controlling potential risks. For safety reasons, materials which are not required should not be included in the radiology control regime so as to reduce the potentially generated radioactive waste, reduce the spread of contamination, and minimize waste volume.

\section{Reuse and/or recycle}

The reuse and/or recycling of radioactive sources should be considered as an alternative to disposal, if possible. The safety of reuse and/or recycling should be reviewed before the operation begins, to ensure that the risk that can occur will be satisfactorily manageable, and the provisions required by regulatory bodies will be met. The reuse of a sealed source must be in accordance with regulations, and its recycling should be performed by the manufacturer. There are two main parameters characteristic of a sealed source, which becomes a spent and disused sealed source, namely a relatively high activity and a relatively long half-life.

A sustainable option for managing disused sealed sources is recycling for further use. If this is not possible, another option for spent and disused sealed sources is sending the sources back to their countries of origin through the suppliers. However, these options can not always be guaranteed, due to various factors such as the manufacturer in the country of origin no longer operating, or the suppliers in the country which uses the sources becoming no longer known or no longer existing because of bankruptcy.

For X-ray equipments, reuse and recycling have been implemented in developed countries. In reusing and/or recycling X-ray equipments, there are four options: (1). refurbishment; (2). reconditioning or repair; (3). reselling or transfer of ownership as second hand equipment; and (4). remanufacturing. Among those four options, refurbishment produces 
the highest quality equipment. There are three reasons that refurbished products are similar to new products: first, the products must also meet the standards (ISO and IEC); second, those products also have the manufacturer's warranty; and third, there are three world-class associations which publish a code of conduct document to facilitate the refurbished product. The aforementioned three associations are the European Coordination Committee of the Radiological, Electromedical and Healthcare IT Industry (COCIR) in the European region, the Medical Imaging \& Technology Alliance (MITA) in the US, and the Japan Industries Association of Radiological Systems (JIRA) in Japan. Those associations who published a code of conduct document titled "Good Refurbishment Practice for Used Medical Equipment". They also establish a "Good Refurbishment Practice" (GRP) label which they grant to refurbished products which fulfill the codes [6,7].

For radiotherapy equipment with teletherapy and brachytherapy equipment with remote afterloading, the situation is very different because there are two objects, the sources and the main equipments themselves, which cause major concerns. Thus, there are two possible courses in reusing, namely merely reusing the radioactive sources, and reusing the entire radiotherapy equipment including the radioactive sources. Additionally, in industrial applications, there are not any provisions yet relating to reuse. Further, the lifetime of radioactive sources for industrial and research applications are not as tightly regulated as for medical applications, although the equipments' manufacturers always give pertinent recommendations regarding the lifetimes in the equipments' manuals. In contrast, in medical fields, there are very tight provisions relating to source lifetimes, as they influence doses received by the patients.

\section{POLICY OF REUSE AND RECYCLE OF SPENT AND DISUSED SEALED SOURCES}

In this chapter, potential legal problems with the practices of reuse and recycle are explained, and a policy change proposed for reuse and recycle of disused sealed sources is explained. This proposal is necessary as presently, there are no specified reuse and recycle policy for such spent and disused sealed sources. The de facto policy presently followed in the field is that the radioactive sources which are stored in BATAN's radioactive waste management facilities in Serpong be reused. The understanding is that radioactive sources stored at the facility had entered the "radioactive waste" regime of the use of sealed sources which had earlier been referred to as SSRW.

Here, the first subsection will describe the currently followed policy, followed by developments which lead to the proposed policy, listed more or less chronologically. A possible legal conflict with the provisions of Act No. 10 Year 1997 is explained in the second subsection, followed in the next two subsections by changes brought forth by the Governmental Regulation No. 27 Year 2002 and No. 29 Year 2008. The last subsection describes how the policy currently followed by BATAN and BAPETEN has been implemented in the past few years.

\section{Policy provisions of present policy}

The policy presently followed by chairpersons of BAPETEN and BATAN allows the reuse of radioactive sources in a facility if they meet the following two conditions:

1. Either one of the following two:

a. The SSRW is to be reused for purely Research \& Development activities by BATAN.

b. The SSRW is to be reused by educational institutions.

2. New licenses have been issued issued by BAPETEN for the reuse of the DSRS or SSRW for $\mathrm{R} \& \mathrm{D}$ or educational purposes.

\section{Potential incompatibility with Act No. 10 Year 1997}

There was a concern, however, that the policies in 4.2 might face legal problems because it was not in accordance with the mandates of Act No. 10 Year 1997 on nuclear power. Specifically, the problem was with the definition of radioactive waste. As specified in the general provisions, radioactive wastes are radioactive substance and/or materials and equipment which have been exposed to radioactivity or become radioactive, due to the operation of nuclear installations, and therefore can no longer be used. Thus, the SSRW was defined as a "radioactive material that can no longer be used" [8].

Additionally, IAEA has also stated clearly that the term "radioactive waste" means radioactive materials in solid, liquid or gas forms which cannot be used anymore, and are controlled as radioactive waste by the regulatory bodies according to appropriate laws and regulations. Further provisions 
on radioactive waste were to be provided by a Government Regulation (GR) [9].

\section{Government Regulation No. 27 Year 2002 and its amendment}

1.1.

In this GR, it is stipulated that radioactive waste (SSRW) will be returned to their countriaszof origin or submitted to the promoting body to be managed [10]

In 2010 an amendment to GR No. 27 was made. One of the main reasons was that the "reuse and recycle" concept needed to be reformulated. The amendment draft has created a paradigm change: the "waste" as a legal object was changed to "waste candidate", namely radioactive sources that are not used anymore (DSRS). Those radioactive sources are to be returned to the country of origin or assigned to the promoting body to be managed. In addition to the waste, "waste candidate" also within the scope of the amendments to GR. No. 27. Thus, the amendments are not compatible with the mandate of article 27 paragraph (2) of Act. No. 10 Year 1997.

Another way to minimize SSRW is by implementing the policy of reexporting DSRS or "waste candidates" with relatively high activities and long half-lives, such as Cs-137, to the country of origin if recycling cannot be performed by BATAN.

For DSRS or "waste candidates" with low activities and short half-lives, the user should submit them to the radioactive waste management, so that industrial and medical users do not have to pay administration costs and the cost of re-exports to the country of origin which is quite expensive. This course of action could be taken, for example, for Ir-192 sealed sources utilized in industrial radiography and brachytherapy remote-afterloading.

\section{The Government Regulation No. 29 Year 2008}

The government regulation no. 29 year 2008 on licensing of ionizing radiation sources and nuclear material utilization provides for the transfer of radioactive substances, as follows:

- Article 4 letter $\mathrm{d}$, for the transfer of radioactive substances and/or ionizing radiation generated for medical purposes; and

- Article 4, letter e, for the transfer of radioactive substances and/or ionizing radiation generated for other than medical purposes [8].
However, those provisions are not applicable to the reuse of spent or disused sealed sources, because the transfer is only allowed for the users which already have the permission and for the same use, as shown in Appendix 1.

\section{Implementation of policy}

The execution of reuse of spent and disused sealed sources can only be conducted under authorization from the BAPETEN and BATAN Chairmen, as shown in Appendix 2. In the last few years, the following reuse operations have been performed according to the provisions for the reuse of "waste candidate" or DSRS:

- PTKMR BATAN, Pasar Jumat, from the utilization of teletherapy (Co-60), 2007.

- STTN, Yogyakarta, from the utilizations of gauging (Co-60, Cs-137, Sr-90) and industrial radiography (Ir-192), 2007.

- PATIR, BATAN, Pasar Jumat, from the utilization of tracer and well logging (Kr-85), 2010.

For example, the reuse of radioactive waste candidate from Co-60 teletherapy into calibration facility is shown in Fig. 1, 2 and 3.

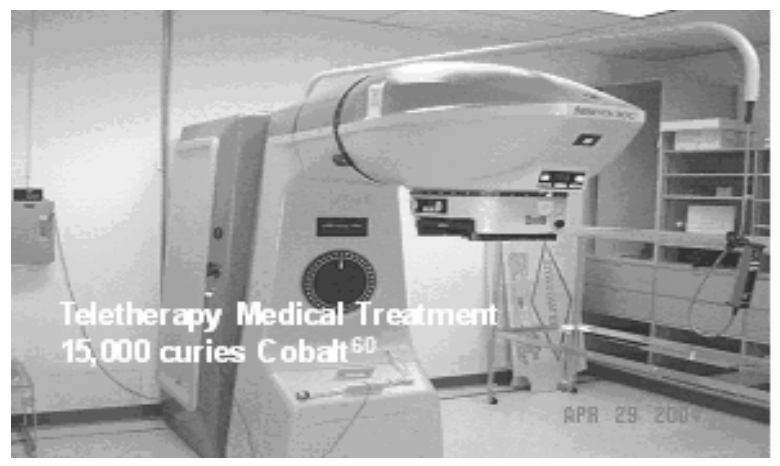

Fig. 1. Co-60 teletherapy equipment (in Use).

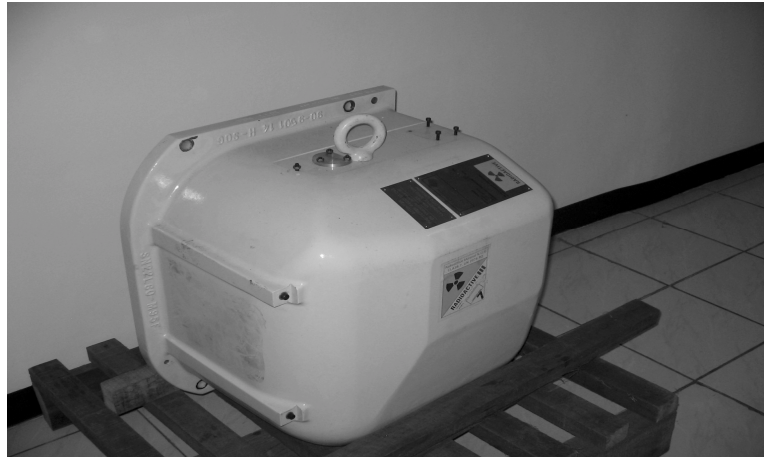

Fig. 2. Container containing radioactive source capsule (spent sealed source) 


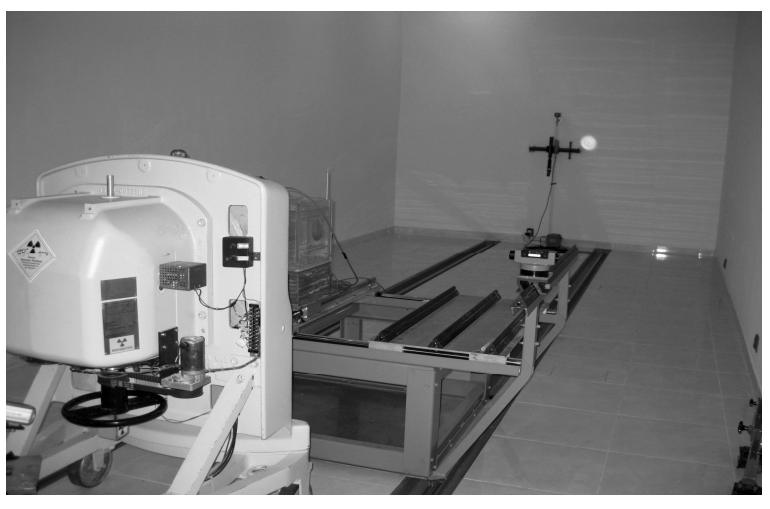

Fig. 3. Calibration Facility (Reuse).

\section{CONCLUSION}

The stipulation regarding the return shipment of radioactive waste to the country of origin in the GR. No. 27 Year 2002 is not very appropriate since it is unusual to ship waste from one country to another. Therefore, the use of term DSRS or "waste candidate" is more precise. It is proposed here that to be in accordance with Act. No. 10 Year 1997, the amendment of GR. No. 27 Year 2002 on radioactive waste management should include the following policy to be followed by BATAN and BAPETEN:

a. Users should state that the sealed sources which are not used anymore in the form of "waste candidates" (spent and disused sealed sources) will be re-exported to their countries of origin or to be sent to the Radioactive Waste Management of BATAN as the Promoting Body.

b. BAPETEN will subsequently authorize BATAN to assess the DSRS or "waste candidate" to determine the next options, whether to reuse, recycle or dispose of them.

c. BATAN is responsible for conveying the results of the radiation safety assessment for reuse or recycling of DSRS or "waste candidates" as one of the permit requirements, as shown in the scheme at the end of this paper.

Although the reuse or recycle of DSRS or waste candidates is not mandated by the Act. No. 10 Year 1997, amendments are being made to the Government Regulation No. 27 Year 2002 in order to facilitate the reuse or recycle operation, especially for radioactives with relative long half-lives.
The amendments will be made because of the needs for, and benefits of, applying the radioactive waste management principles. To avoid legal conflicts, in the amendment government regulation no.27 year 2002 on management of radioactive waste, there will be a recommendation for a new scheme in the management of radioactive waste to facilitate the application of the principles of reduce, reuse, and recycle, as shown in Appendix 3.

\section{REFERENCES}

1. Anonymous, Training Material of Disused Sealed radioactive Source, IAEA, Jakarta, Indonesia (2010).

2. Anonymous, Training Material of Security of Radioactive Source, IAEA, Sydney (2009).

3. Anonymous, Guidance on the Import and Export of Radioactive Sources, IAEA, Vienna (2005).

4. Anonymous, Management of Disused Long Lived Sealed Radioactive Sources, IAEATECDOC-1357, IAEA, Vienna (2003).

5. Anonymous, Management of Waste from the Use of Radioactive Material in Medicine, Industry, Agriculture, Research and Education, Waste, IAEA Safety Standard Series No. WSG-2.7, IAEA, Vienna (2005).

6. Anonymous, Good Refurbishment Practice for Medical Imaging Equipment, COCIR-JIRAMITA, Brussels (2009).

7. T. Marpaung, Literature Study on Tecnical Criteria of Importation of New and Used X-ray Medical Equipment for Radiology, BAPETEN, Jakarta (2010). (In Indonesian)

8. Anonymous, Act No. 10 Year 1997 on Nuclear Energy, BAPETEN, Jakarta (2000). (In Indonesian).

9. Anonymous, Government Regulation No. 33 Year 2007 on Ionizing Radiation Safety and Security of Radioactive Source, Jakarta (2007). (In Indonesian).

10. Anonymous, Government Regulation No. 29 Year 2008 on License of Utilization of Ionizing Radiation Source and Nuclear Material, BAPETEN, Jakarta (2008). (In Indonesian). 


\section{Appendix 1}

Scheme of sealed source radioactive waste management based on GR. No. 29 Year 2008.

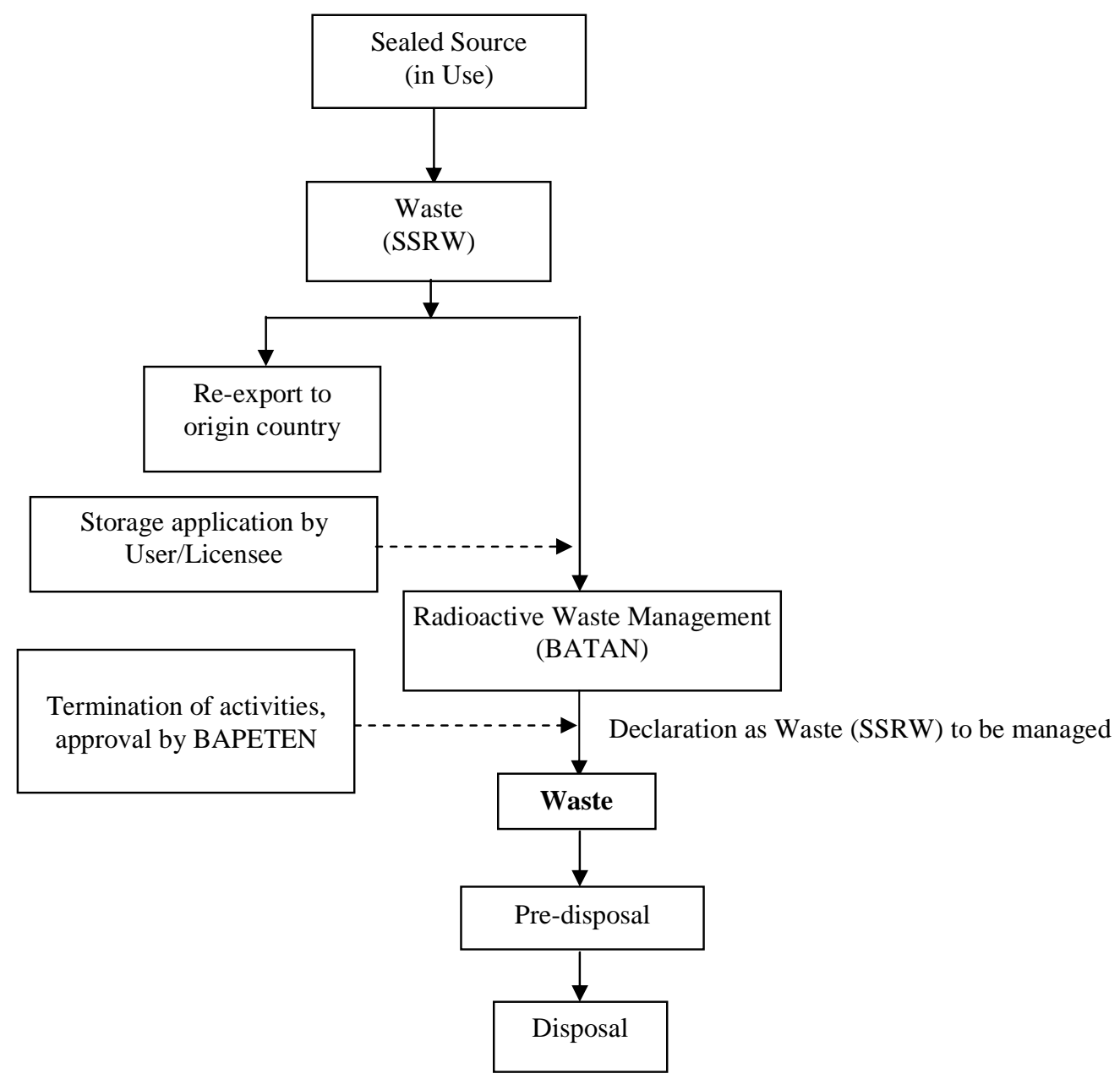


Appendix 2

Scheme of sealed source radioactive waste management based on policy.

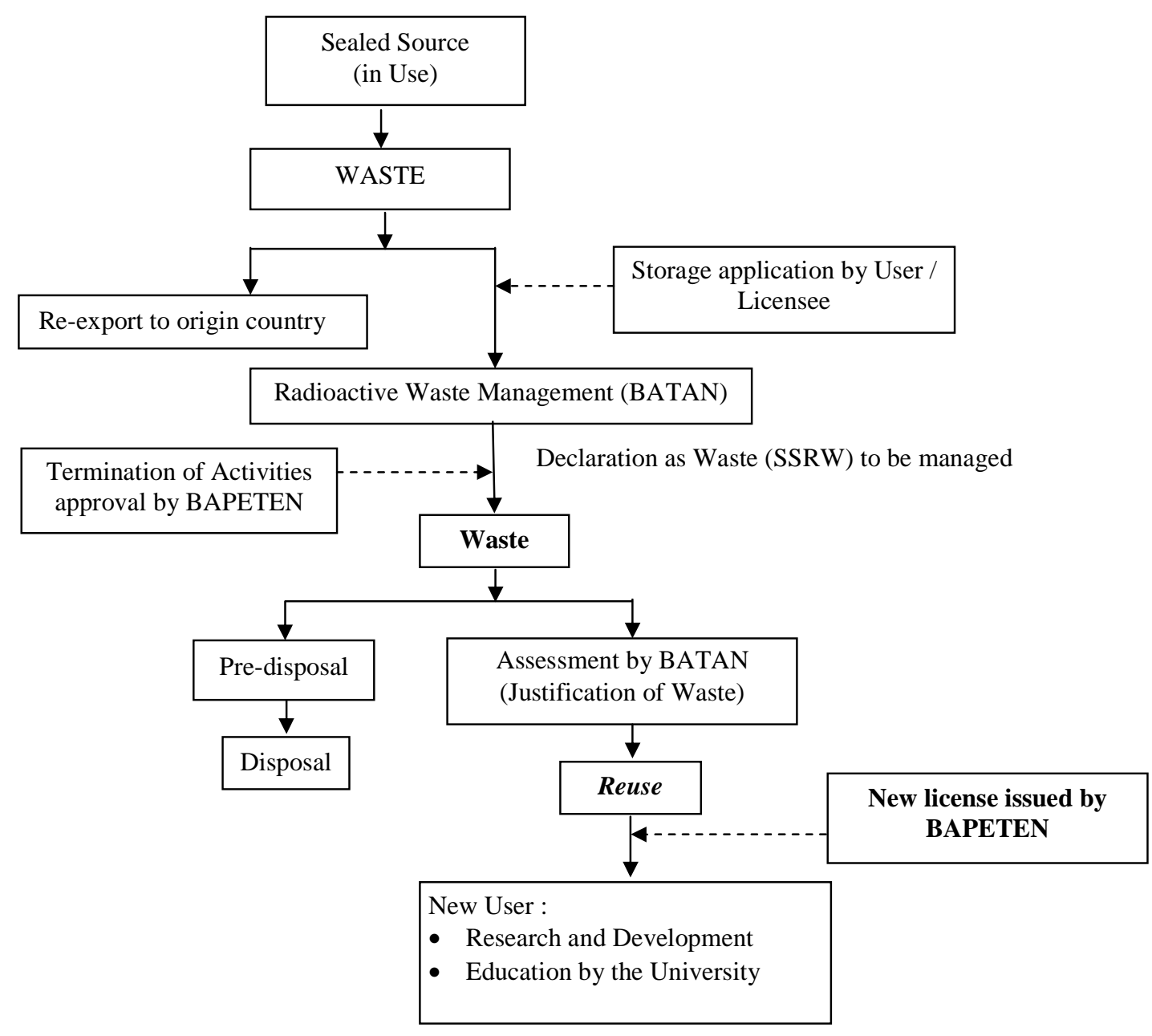




\section{Appendix 3}

Recommendation scheme of sealed source radioactive waste management.

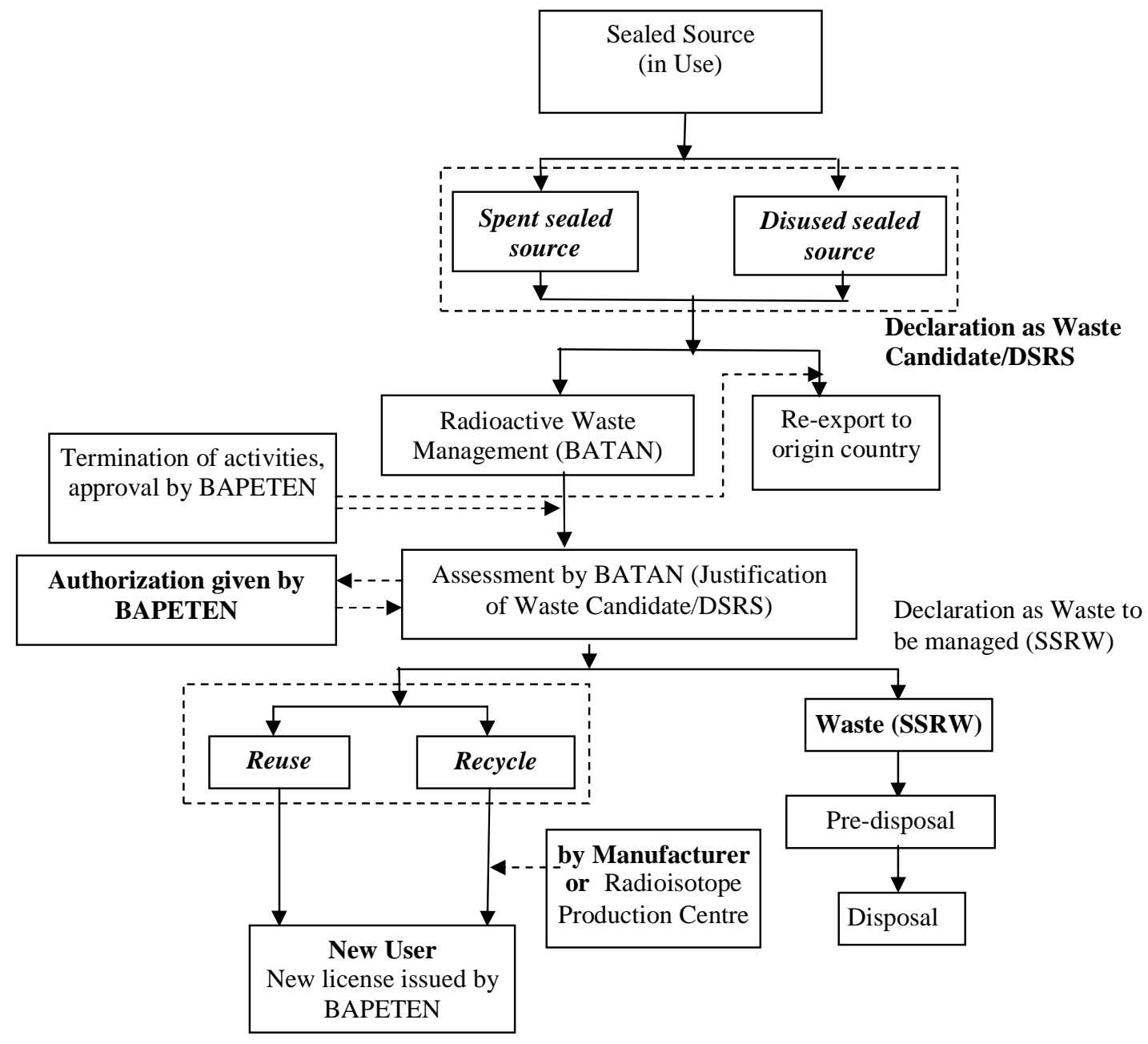

